\title{
CƠ HỘI VÀ THÁCH THỬC ĐỐI VỚI SẢN XUÂT NÔNG SẢN \\ KHI VIỆT NAM GIA NHẬP AEC
}

\section{Opportunities and challenges of agricultural production once Vietnam joins in AEC}

ThS. Đỗ Hải Yến*

\section{TÓM TẮT}

Cộng đồng kinh tế ASEAN (AEC) chính thức thành lập vào cuối năm 2015, đây là một buớc ngoặt đánh dấu sụ hội nhập một cách toàn diện của các nền kinh tế trong khu vực Đông Nam Á. Với mục tiêu nhằm tạo dưng một thị truờng thống nhất cho các quốc gia thành viên, thúc đẩy dòng chu chuyển tụ do của hàng hóa, dịch vu, đầu tu và lao động có tay nghề trong khối. Việc gia nhập AEC đem lại nhiều co hội cho nông sản Việt Nam, tuy nhiên bên cạnh đó sản xuất nông sản nuớc ta cũng đối mặt với nhiều thách thức nhu: chất luợng, mẫu mã nông sản hàng hóa còn kém; các nguồn lục đầu tư cho sản xuất nông sản hàng hóa còn thiếu, nhỏ lẻ, manh mún và chura đồng bộ... Đâu là co hội cho sản xuất nông sản Việt Nam? Nhũng thách thức nào cần vượt qua để phát huy tiềm năng, lợi thế trong sản xuất nông nghiệp? Giải pháp nào để đua nông sản Việt Nam hội nhập với thị trường khu vực và quốc tế? Là nhũ̃ng nội dung cơ bản của bài viết này.

Từ khóa: $A E C$, co hội, giải pháp, thách thức, sản xuất nông sản.

\begin{abstract}
ASEAN Economic Community ( AEC) will be formally established in the late of 2015, this is a turning point marking the comprehensive integration of the economies in Southeast Asian countries. With the aim of creating a single market for the Member States, promoting free flow stream of goods, services, investment and skilled labor in the region. Joining AEC create opportunities for Vietnam's agricultural products. However, there are many challenges, such as the output of agricultural products is not much; quality, form of agricultural products is not good; investment resources for producing agricultural products is lack, small, fragmented and not uniform ... Which opportunity is for Vietnam's agricultural products? What challenges must be overcome in order to exploit the potentials and advantages in agricultural production? Which solutions help Vietnam's agricultural products integrate regional and international markets? Are the basic contents of this article.
\end{abstract}

Keywords: AEC, opportunities, solutions, challenges, agricultural production.

\section{Mở đầu}

Cộng đồng kinh tế ASEAN (ASEAN Economic Community, viết tắt là AEC) chính thức thành lập vào cuối năm 2015 là một bước ngoặt đánh dấu sự hội nhập một cách toàn diện của các nền kinh tế trong khu vực Đông Nam Á. Mục tiêu của AEC là nhằm tạo dựng một thị trường thống nhất cho các quốc gia thành viên, thúc đẩy dòng chu chuyển tự do của hàng hóa, dịch vụ, đầu tư và lao động có tay nghề trong khối. Sau khi thành lập AEC sẽ tạo ra một khu vực kinh tế công bằng, có năng lực cạnh tranh cao và hội nhập đầy đủ vào nền kinh tế toàn cầu. Lợi ích mà các nước thành 
viên có được khi gia nhập AEC là tăng trưởng kinh tế nhanh hơn, thu hút trực tiếp đầu tư nước ngoài (FDI) mạnh mẽ hơn, phân bổ nguồn lực tốt hơn, tạo ra nhiều việc làm và tăng cường năng lực sản xuất cũng như tính cạnh tranh cho các doanh nghiệp trong mỗi nước. Điều đó sẽ có những tác động, ảnh hưởng nhất định tới nền kinh tế của mỗi quốc gia thành viên nói chung và nền kinh tế của Việt Nam nói riêng, mà trong đó nông nghiệp được đánh giá là lĩnh vực chịu nhiều tác động.

Tham gia AEC sẽ giúp Việt Nam tăng thêm khối lượng trao đổi thương mại với các nước trong khu vực. Trong đó, thương mại nông sản giữ một vị trí quan trọng với gạo, thủy sản, rau quả... là những mặt hàng chính Việt Nam xuất sang thị trường này, với trị giá chiếm khoảng $30 \%$ tổng kim ngạch xuất khẩu của Việt Nam sang ASEAN. Thực tế trong những năm gần đây, tình hình xuất khẩu nông sản của Việt Nam đã giành được nhiều thành tựu đáng kể. Xuất khẩu nông sản chiếm tỷ trọng cao trong tổng kim ngạch xuất khẩu của nước ta và tương đối ổn định. Theo báo cáo của Bộ Nông nghiệp và Phát triển nông thôn, tính đến hết tháng 7 năm 2015, giá trị xuất khẩu các mặt hàng nông sản chính ước đạt 8,2 tỷ USD, giảm 5,7\% so với cùng kỳ năm trước, giảm mạnh ở các mặt hàng như cà phê (giảm 33,7\%), cao su (giảm 9,2\%) và gạo giảm 8,3\% so với cùng kỳ năm 2014. (Báo cáo ngành Nông nghiệp và Phát triển nông thôn, tháng 7/2015).

Bên cạnh những mặt tích cực và lợi ích từ việc gia nhập AEC đem lại, sản xuất nông sản của Việt Nam sẽ phải cạnh tranh gay gắt với hàng hóa nông sản của các nước khác trong ASEAN. Khi hàng hóa ở tất cả các nước thành viên đều có mức thuế như nhau thì sức cạnh tranh sẽ tập trung vào chất lượng và giá bán sản phẩm. Hàng nông sản Việt Nam sẽ đón nhận những cơ hội mới, song cũng phải đương đầu với nhiều thách thức. Bài viết tập trung vào phân tích điểm mạnh, điểm yếu, cơ hội và thách thức đối với sản xuất nông sản Việt Nam, trên cơ sở đó tận dụng những điểm mạnh và cơ hội có được để khắc phục những điểm yếu và vượt qua thách thức, hướng tới một thị trường nông sản phát triển bền vững.

Phương pháp nghiên cứu chủ yếu của bài viết: Sử dụng phương pháp thống kê mô tả và phương pháp phân tích ma trận SWOT.

\section{Phân tích SWOT cho sản xuất nông sản Việt Nam}

\section{1. Điểm mạnh của sản xuất nông sản Việt Nam}

- Trong co cấu kinh tế của Việt Nam thì nông nghiệp vẫn là ngành co bản chiếm tỷ trọng cao. Lực lượng lao động tham gia sản xuất nông nghiệp dồi dào, hơn 70\% người trong độ tuổi lao động làm ngành nông nghiệp. Thêm vào đó, tiền lương nhân công rẻ, trung bình tiền lương nhân công ở Việt Nam rơi vào khoảng xấp xỉ 2-3 USD/ ngày công lao động, trong khi đó tiền lương nhân công ở một số nước khác như Thái Lan cao gấp 2-3 lần. Do vậy, sản xuất nông nghiệp nói chung cũng như sản xuất các mặt hàng nông sản nói riêng thực sự có được lợi thế.

- Do có điều kiện tụ nhiên thuận lợi nên Việt Nam là nước có thế mạnh trong những mặt hàng nông sản nhiệt đới như: gạo, cà phê, chè, cao su, hạt điều, tiêu, thủy sản... Bên cạnh đó chúng ta có thể sản xuất một số loại nông sản như rau, củ, quả mang tính chất đặc thù mà nhiều quốc gia khác không có.

- Chi phí sản xuất thấp: So với các mặt hàng xuất khẩu thuộc lĩnh vực công nghiệp như giầy da, điện tử... với mức kim ngạch xuất khẩu thu về như nhau thì tỷ lệ chi phí cho sản xuất các sản phẩm nông nghiệp thấp hơn nhiều. Do đó, thu nhập ròng tính trên một đơn vị kim ngạch xuất khẩu 
của hàng nông sản sẽ cao hơn hàng công nghiệp. Với các điều kiện thời tiết, khí hậu, đất đai, lao động, kinh nghiệm sản xuất, môi trường sinh thái, tài nguyên rừng, biển... thuận lợi cho sản xuất nhiều loại nông sản mang lợi thế cạnh tranh, giá thành sản xuất thấp.

- Thể chế chính trị, môi truờng kinh doanh hấp dẫn: Việt Nam là đất nước có thể chế chính trị tương đối ổn định, môi trường đầu tư, hệ thống luật pháp ngày càng được hoàn thiện, thích ứng với tiến trình tự do hóa thương mại toàn cầu.

\section{2. Điểm yếu của sản xuất nông sản Việt Nam}

Bên cạnh những điểm mạnh tạo nên lợi thế cho sản xuất nông sản hàng hóa, còn rất nhiều khó khăn, hạn chế khiến sản xuất nông sản Việt Nam chưa thực sự phát triển mạnh so với tiềm năng vốn có, đó là:

- Các nguồn lực cho sản xuất kinh doanh ngành nông nghiệp còn nhỏ lẻ, manh mún, thiếu và chưa đồng bộ: Đất đai, lao động, vốn, khoa học kỹ thuật, cơ sở hạ tầng... Sản xuất còn manh mún, nhỏ lẻ, tự phát, mang tính phong trào, phụ thuộc nhiều vào các yếu tố tự nhiên;

- Sản xuất nông sản hàng hóa còn thiếu quy hoạch, thiếu chiến lược, mang tính phong trào. Sản xuất còn mang tính thủ công, năng suất lao động thấp, hình thức, mẫu mã sản phẩm chưa đẹp, chất lượng sản phẩm chưa cao, giá thành sản xuất chưa cạnh tranh. Vấn đề "Được mùa, mất giá" vẫn lặp đi lặp lại;

- Cơ cấu nông sản hàng hóa còn mất cân đối: Sản xuất nông sản ở Việt Nam còn chú trọng khá nhiều vào cây lúa. Mức độ đầu tư, nghiên cứu, đất đai, lao động và tài chính cho loại cây trồng này khá cao. Việc chú trọng quá nhiều vào lúa gạo cũng khiến sản xuất nông sản hàng hóa của Việt Nam khai thác chưa hiệu quả nguồn lợi từ thị trường quốc tế dành cho một số nông sản khác, đặc biệt là rau, củ, quả, cây dược liệu... mà trên thế giới thị trường rau, hoa quả có giá trị lớn gấp 7 lần so với thị trường lúa gạo. Tình trạng mất cân đối cơ cấu cây trồng này không chỉ do Việt Nam chưa có định hướng phát triển phù hợp với nhu cầu thực tế của thị trường thế giới, mà còn do người nông dân và các doanh nghiệp vẫn phải đối diện với nhiều rủi ro nên không dám đầu tư vào những ngành xuất khẩu đòi hỏi đầu tư công nghệ cao và có hệ thống, mà chỉ tập trung sản xuất các mặt hàng nông phẩm thô như lúa gạo, cà phê hay chè. Chính sách đất nông nghiệp chỉ cho phép sử dụng có thời hạn cũng làm tăng rủi ro cho người sử dụng đất, càng khiến các doanh nghiệp trong và ngoài nước không mặn mà với việc đầu tư có chiều sâu cho công nghệ cao trong nông nghiệp. Suốt 10 năm qua, hầu hết các nông phẩm có tốc độ tăng xuất khẩu cao của Việt Nam lại chính là những sản phẩm có tốc độ giảm xuất khẩu của thế giới và ngược lại. Điều này phản ánh rất rõ khả năng phản ứng và thích nghi rất hạn chế, rất thụ động với nhu cầu thị trường thế giới cả trong sản xuất, chế biến và xúc tiến kinh doanh thương mại;

- Hệ thống cơ sở hạ tầng, máy móc thiết bị, công nghệ sản xuất và sau thu hoạch còn lạc hậu: Chúng ta chưa xây dựng được chuỗi ngành hàng xuyên suốt và đồng bộ, nên khi lượng nông sản thu hoạch chính vụ đạt đỉnh thì chúng ta gặp những khó khăn như: Hệ thống vận tải yếu kém đã cản trở vận chuyển đường dài các nguyên liệu và thành phẩm; thiếu kho tàng để tạm trữ sản phẩm sau thu hoạch, thiếu nhà mát để lưu kho; công nghệ chế biến lạc hậu, vật liệu bao bì chưa tốt gây tổn thất lớn trong thu hoạch, bảo quản và chế biến, làm giảm chất lượng sản phẩm. Bên cạnh đó, quan 
trọng hơn hết là thiếu thị trường để tiêu thụ một lượng hàng "thô" dồi dào trong khi hoạt động chế biến còn rất hạn chế. Thêm vào đấy, nông dân vào thời điểm thu hoạch cũng đã hết tiền nên phải bán tháo để lấy vốn cho kỳ tới. Khâu thu hoạch, bảo quản, chế biến, tiêu thụ còn chưa đáp ứng được yêu cầu;

- Sản xuất nông sản chưa quan tâm đến vệ sinh an toàn thực phẩm, bảo vệ môi trường sinh thái và phát triển bền vững. Việc sử dụng phân bón hóa học, thuốc trừ sâu, thuốc diệt cỏ, thuốc bảo quản một cách tùy tiện, vượt quá giới hạn cho phép, dẫn đến thoái hóa, đất, ô nhiễm nguồn nước, gây hại sức khỏe cho công đồng, làm mất niềm tin của người tiêu dùng, dẫn đến nhiều hàng hóa nông sản bị tẩy chay, không xuất khẩu được;

- Thị trường đầu ra cho nông sản không ổn định, bởi tất cả các khâu từ sản xuất, thu hoạch, bảo quản, chế biến, xây dựng thương hiệu, tiêu thụ nông sản đều thiếu sự quy hoạch, thiếu tính chiến lược, thiếu sự đồng bộ và thiếu sự đầu tư thỏa đáng... gây ra những bất ổn và rủi ro đối với việc sản xuất và tiêu thụ nông sản;

- Các sản phẩm nông sản ở Việt Nam phần lớn chưa có được thương hiệu: Theo khảo sát của Cục Sở hữu trí tuệ trong năm 2012, Việt Nam có tới 933 sản phẩm nông nghiệp, dịch vụ đặc thù gắn với 721 địa danh trên cả nước, trong đó có 800 sản phẩm nổi tiếng. Tuy nhiên, số lượng sản phẩm có chỉ dẫn địa lý được đăng ký bảo hộ chiếm tỷ lệ rất nhỏ, chỉ có 136 thương hiệu sản phẩm có đăng ký bảo hộ. Như vậy, rõ ràng là tiềm năng của nông sản Việt Nam đang bị bỏ lỡ rất lớn. Chúng ta luôn dẫn đầu về xuất khẩu cà phê, hồ tiêu, hạt điều và nhiều loại trái cây của Việt Nam như vải, nhãn, bưởi, thanh long... được ưa chuộng trên thế giới nhưng vẫn chưa xây dựng được thương hiệu riêng. Điều này khiến cho $90 \%$ nông sản xuất khẩu trong thời gian qua chỉ biết đi theo hướng xuất khẩu nguyên liệu thô với lợi ích kinh tế mang lại rất thấp. Trong khi đó, từ các nguyên liệu thô này sau khi nhập sang các nước khác được chế biến, mang thương hiệu của họ và bán với giá rất cao.

\subsection{Co hội cho sản xuất nông sản khi Việt Nam gia nhập AEC}

- Mở rộng thị truờng, xuất khẩu nông sản gia tăng: Gia nhập AEC, các mặt hàng nông sản có cơ hội được xuất khẩu ra các nước khác nhiều hơn với thuế suất thấp. Đặc biệt có thể xuất sang thị trường Singapore - đây là cổng chu chuyển hàng hóa với thế giới. Việc thuế suất giảm xuống rất có lợi cho nhà sản xuất và chế biến. Hiện nay, đối với nông sản xuất khẩu, các doanh nghiệp chế biến và xuất khẩu nông sản, quan trọng nhất là đầu ra, nếu đầu ra không phải chịu thêm loại thuế nào vào sản phẩm, nông dân sẽ không chịu cảnh bị ép giá, hạ giá. Đây sẽ là cơ hội lớn cho việc xuất khẩu các mặt hàng nông sản của Việt Nam.

- Tăng cuờng các nguồn lực cho đầu tu: Sau khi gia nhập AEC, các nhà đầu tư nước ngoài sẽ mang đến Việt Nam những nguồn lực đầu tư cho phát triển ngành nông nghiệp như: vốn, khoa học kỹ thuật, máy móc thiết bị, trình độ quản lý... để tăng cường năng lực đầu tư, mở rộng quy mô sản xuất kinh doanh hàng hóa nông sản ở tất cả các khâu: sản xuất, thu hoạch, chế biến, tiêu thụ. Tăng năng suất, hạ giá thành, đảm bảo các tiêu chuẩn về số lượng, chất lượng, mẫu mã, giá trị cho nông sản là những điều kiện rất cần thiết để tăng khả năng cạnh tranh, phát triển thị trường nông sản Việt Nam, đáp ứng nhu cầu sản xuất, tiêu dùng trong nước và xuất khẩu thế giới. 
- Cơ hội liên doanh, liên kết, hợp tác quốc tế: Việc liên doanh, liên kết, hợp tác quốc tế trong các lĩnh vực đầu tư, đào tạo nguồn nhân lực chất lượng cao cho các ngành nói chung và cho sản xuất nông sản hàng hóa nói nói riêng trở nên thuận lợi, dễ dàng. Hơn nữa, các doanh nghiệp Việt Nam còn có cơ hội tiếp cận với thị trường rộng lớn hơn với các đối tác như Trung Quốc, Nhật Bản, Hàn Quốc, Australia, New Zealand thông qua các hiệp định thương mại tự do riêng giữa ASEAN và các nước.

- Cơ hội tăng cường nghiên cứu, ứng dụng khoa học - kỹ thuật - công nghệ hiện đại, tiên tiến vào sản xuất, chế biến và tiêu thụ nông sản nhằm đảm bảo năng suất, chất lượng và hiệu quả kinh tế, đẩy mạnh công nghệ sau thu hoạch, tập trung phát triển sản xuất nông nghiệp theo hướng hữu cơ, nông nghiệp sinh thái bền vững. Bên cạnh đó tăng cường hợp tác quốc tế trong đào tạo nguồn nhân lực cho ngành nông nghiệp, đáp ứng yêu cầu nguồn nhân lực chất lượng cao trong hoạt động sản xuất và tiêu thụ nông sản hàng hóa.

\subsection{Thách thức đối với sản xuất nông sản khi Việt Nam gia nhập AEC}

- Chất lượng nông sản: Bên cạnh những thuận lợi từ việc bán hàng không thuế, một trong những thách thức lớn nhất đối với thị trường nông sản của ta đó là do tập quán sản xuất của nông dân Việt Nam. Tình trạng nông dân lạm dụng thuốc bảo vệ thực vật, thuốc kháng sinh để bảo vệ cây trồng, vật nuôi trước những đợt bệnh, dịch hại. Mặc dù phía doanh nghiệp hợp tác sản xuất, thu mua có tác động và hướng dẫn họ cách sản xuất an toàn, hiệu quả thì mức độ này cũng chỉ giảm chứ không chấm dứt triệt để. Hơn nữa những vùng đất canh tác, sản xuất của Việt Nam đều được khai thác từ lâu và thời gian nghỉ đất, phơi đất, phơi trại quá ngắn để tái sản xuất nên mức độ tiêu diệt những mầm bệnh tiềm ẩn không cao. Vì vậy, điểm yếu về chất lượng sản phẩm sẽ là thách thức lớn cho thị trường nông sản Việt Nam.

- Sức ép hạ giá: Khi tham gia AEC và các FTA cũng có nghĩa các thương lái nước ngoài có quyền thu mua trực tiếp nông sản của Việt Nam ngay trên đồng ruộng. Khi đó, doanh nghiệp các nước hầu như sẽ nắm được giá thành sản xuất, họ có thể điều phối sản lượng nông sản, thậm chí diện tích gieo trồng của nông dân. Khi đó nông dân dễ trở nên bị động trong bán hàng, bị thương lái nước ngoài ép giá, hạ giá dẫn đến không có lợi nhuận.

- Cạnh tranh gay gắt: Điều kiện để phát triển các sản phẩm nông nghiệp của Việt Nam có nhiều điểm tương đồng với các nước khác trong khu vực như: cơ cấu kinh tế còn lạc hậu, thực hiện chiến lược công nghiệp hoá theo hướng xuất khẩu, cạnh tranh nhau trong thu hút đầu tư và công nghệ nước ngoài... Tính chất tương đồng này sẽ làm tăng mức độ gay gắt của tình trạng cạnh tranh để xuất khẩu nông sản giữa các nước. Đặc biệt sau khi thành lập, AEC hình thành sẽ tạo ra thị trường chung, không còn rào cản hàng hóa, dịch vụ, vốn... Hàng hoá ở các nước thành viên ASEAN sẽ có mức thuế ưu đãi như nhau, khi đó sức cạnh tranh sẽ tập trung vào chất lượng và giá bán của sản phẩm. Trong khi đó, với thiết bị, công nghệ hiện nay, sản phẩm của doanh nghiệp Việt Nam khó có thể cạnh tranh với sản phẩm xuất khẩu của các nước trong khối. Hơn nữa, việc cạnh tranh lại diễn ra ngay trên sân nhà, khi mà các loại nông sản nước ngoài có chất lượng cao, hình thức mẫu mã đẹp, giá cả thấp hơn do hàng rào thuế quan đã gỡ bỏ dễ dàng thâm nhập vào Việt Nam và cạnh tranh với nông sản trong nước. Theo Bộ trưởng Cao Đức Phát: "Nếu không có biện pháp phù hợp 
Việt Nam sẽ trở thành thị trường tiêu thụ của các nước, nông dân liên quan không còn thu nhập tù ngành này. Hội nhập là để mỗi nước tham gia phát huy lợi thế của mình, nước nào cũng muốn bán hàng, nhung muốn cạnh tranh được thì phải hạ giá thành, nâng cao chất luợng hàng hóa. Muốn làm được điều này, ngoài sụ cố gắng, nỗ lực của Nhà nước, suy cho cùng vấn đề thực hiện vẫn là bản thân các doanh nghiệp và bà con nông dân”.

- Hàng loạt các tiêu chuẩn đặt ra đối với nông sản Việt Nam: Khi các hàng rào thuế quan gỡ bỏ, cũng là lúc các hàng rào phi thuế quan đặt ra nghiêm ngặt hơn. Các tiêu chuẩn yêu cầu đối với nông sản về chất lượng, thương hiệu, vệ sinh an toàn thực phẩm, kiểu dáng mẫu mã, nguồn gốc xuất xứ, nhãn hiệu, bản quyền, quyền sở hữu trí tuệ, chống bán phá giá... hàng loạt các vấn đề rất mới mà những nhà sản xuất nông sản của chúng ta (chủ yếu là nông dân) vẫn còn lúng túng. Nếu nông sản Việt Nam không đáp ứng được các yêu cầu nghiêm ngặt của hàng rào phi thuế quan (các rào cản kỹ thuật) thì sẽ bị trả lại ngay tại cửa khẩu biên giới nước nhà.

- Sự chênh lệch và trình độ phát triển so với các nước ASEAN cả về quy mô vốn, trình độ khoa học công nghệ, tay nghề lao động. Các chủ thể sản xuất kinh doanh nông sản hàng hóa của Việt Nam còn rất nhỏ bé cả về quy mô hoạt động, năng lực tài chính, trình độ, kinh nghiệm quản lý, điều hành. Đặc biệt khi tham gia vào $\mathrm{AEC}$, Việt Nam phải đối mặt với sự chênh lệch về trình độ phát triển so với các nước ASEAN - 6, thể hiện cả ở quy mô vốn của nền kinh tế, các doanh nghiệp, trình độ khoa học kỹ thuật, tay nghề lao động... Thời điểm cộng đồng ASEAN bắt đầu có hiệu lực vào cuối năm 2015, các doanh nghiệp Việt Nam sẽ phải đối mặt với sức ép cạnh tranh từ hàng hóa nhập khẩu, sản phẩm, dịch vụ, đầu tư của các nước ASEAN, đặc biệt là khi các nước $A S E A N$ loại bỏ các hàng rào phi thuế quan. Một số ngành sẽ phải thu hẹp sản xuất, thậm chí đóng cửa.

\section{Giải pháp thúc đẩy phát triển sản xuất nông sản khi Việt Nam gia nhập AEC}

Phân tích SWOT cho sản xuất nông sản Việt Nam nhằm xác định những điểm mạnh, điểm yếu, cơ hội và thách thức đặt ra trong tiến trình hội nhập $\mathrm{AEC}$, từ đó đưa ra những giải pháp nhằm tranh thủ cơ hội, vượt qua thách thức để phát triển sản xuất nông sản của Việt Nam. Để nông sản Việt Nam có thể đáp ứng nhu cầu sản xuất và tiêu dùng trong nước, đồng thời có đủ sức cạnh tranh để vươn ra thị trường thế giới, tác giả bài viết đề xuất một số giải pháp sau:

- Đánh giá tổng thể những tiềm năng, lợi thế trong phát triển nông sản hàng hóa ở Việt Nam, từ đó quy hoạch các vùng sản xuất nông sản hàng hóa tập trung, quy mô lớn để tạo ra khối lượng nông sản đạt năng suất, chất lượng và hiệu quả, đáp ứng nhu cầu sản xuất và tiêu dùng của thị trường trong nước và xuất khẩu. Khai thác tiềm năng và lợi thế cạnh tranh để phát triển những hàng hóa nông sản đặc trưng của từng vùng, miền. Bộ Nông nghiệp và Phát triển Nông thôn cần phải xác định diện tích canh tác cho từng chủng loại mặt hàng, cần có những khuyến cáo, cảnh báo kịp thời cho từng vùng, từng địa phương khi diện tích canh tác có xu hướng vượt ngưỡng.

- Hoàn thiện cơ chế chính sách, cụ thể hóa và đẩy mạnh việc triển khai thực hiện các chính sách cho phát triển nông nghiệp: chính sách đất đai, vốn, khoa học kỹ thuật, tiêu thụ nông sản, phát triển nguồn nhân lực, đầu tư cơ sở hạ tầng; liên kết, hợp tác trong phát triển nông nghiệp; xây dựng 
thương hiệu và quyền sở hữu trí tuệ, phát minh, sáng chế; chính sách xuất khẩu nông sản; hàng rào thuế quan và phi thuế quan trong xuất - nhập khẩu nông sản hàng hóa...

- Xây dựng thương hiệu cho nông sản Việt Nam. Phát triển những thương hiệu nông sản có chất lượng cao, bền vững, đảm bảo các tiêu chuẩn trong nước và quốc tế. Muốn vậy điều cần thiết phải có sự kết hợp chặt chẽ trong tất các các khâu hình thành nên chuỗi giá trị sản phẩm: Sản xuất, thu hoạch, bảo quản, chế biến, thiêu thụ.

- Phát triển thị trường nông sản Việt Nam theo hướng: Đáp ứng nhu cầu sản xuất và tiêu dùng trong nước, tìm kiếm thị trường xuất khẩu sang các nước trong khu vực và thế giới. Xây dựng chiến lược phát triển nông sản hàng hóa chất lượng cao theo hướng hiệu quả, bền vững. Hạn chế đến mức tối đa việc sử dụng các hóa chất trong sản xuất, bảo quản, chế biến nông sản. Sản xuất nông sản hàng hóa theo hướng xuất phát từ nhu cầu của thị trường, lấy thị trường làm căn cứ để xây dựng chiến lược quy hoạch vùng và sản xuất nông sản hàng hóa. Cần xúc tiến thương mại để mở rộng thị trường cả xuất khẩu lẫn tiêu thụ nội địa. Cần nắm bắt thông tin chính xác về nhu cầu của thị trường và khả năng cạnh tranh của hàng hóa để làm cơ sở cho việc sản xuất nông sản hàng hóa.

- Phát triển mô hình liên kết "4 nhà": liên kết "4 nhà" trong sản xuất nông nghiệp hiện đại được khẳng định là ưu việt nhất hiện nay. Muốn liên kết sản xuất, tiêu thụ sản phẩm nông nghiệp được cải thiện, cần đảm bảo sự hài hòa lợi ích giữa các bên tham gia, xây dựng được sự tin tưởng, trách nhiệm giữa các bên tham gia. Cụ thể như, vừa phải đảm bảo giảm chi phí đầu tư, tăng thu nhập cho người nông dân, vừa giảm giá thành sản phẩm, ổn định lợi nhuận cho các doanh nghiệp.

- Phát triển công nghiệp sản xuất các tư liệu sản xuất phục vụ cho sản xuất nông nghiệp (máy móc, thiết bị, phân bón, thuốc bảo vệt thực vật, thức ăn gia súc...); phát triển các doanh nghiệp thu mua, bảo quản, chế biến, tiêu thụ nông sản.

- Tăng cường nghiên cứu, ứng dụng khoa học - kỹ thuật - công nghệ hiện đại, tiên tiến vào sản xuất, chế biến và tiêu thụ nông sản nhằm đảm bảo năng suất, chất lượng và hiệu quả kinh tế. Tập trung phát triển sản xuất nông nghiệp theo hướng hữu cơ, nông nghiệp sinh thái bền vững. Đầu tư phát triển cơ sơ hạ tầng phục vụ phát triển nền nông nghiệp sản xuất hàng hóa. Đẩy mạnh công nghệ sau thu hoạch.

- Tăng cường đầu tư cho đào tạo và phát triển nguồn nhân lực chất lượng cao phục vụ sự nghiệp phát triển nền nông nghiệp sản xuất hàng hóa hiệu quả, bền vững, hội nhập kinh tế quốc tế. Đổi mới chương trình đào tạo nguồn nhân lực của các trường có đào tạo các chuyên ngành Kinh tế nông nghiệp; phát triển nông thôn; trồng trọt, chăn nuôi, khoa học nông nghiệp; bảo quản chế biến nông sản.... theo hướng đào tạo gắn lý thuyết với thực hành, thực tế; tăng cường các kiến thức pháp luật, ngoại ngữ, hội nhập kinh tế quốc tế, chú trọng bồi dưỡng năng lực tổ chức, quản lý, lãnh đạo. Tăng cường hợp tác quốc tế trong đào tạo nguồn nhân lực cho ngành nông nghiệp, đáp ứng yêu cầu nguồn nhân lực chất lượng cao trong hoạt động sản xuất và tiêu thụ nông sản hàng hóa.

- Phát huy vai trò của các tổ chức, hội nghề nghiệp: hội nông dân trung ương và các địa phương, các hiệp hội ngành nghề, và các hợp tác xã cần sát sao với tình hình sản xuất để một mặt tư vấn cho nông dân, và mặt khác đưa ra những kiến nghị chính sách kịp thời. 


\section{Kết luận}

Phát triển sản xuất nông sản hàng hóa cần được xác định là nhiệm vụ trọng tâm, mang tầm chiến lược trong kế hoạch phát triển kinh tế - xã hội của Việt Nam. Đánh giá thực trạng sản xuất nông sản Việt Nam trong những năm qua, chúng ta thấy Việt Nam có rất nhiều tiềm năng, lợi thế tạo nên thế mạnh trong sản xuất và tiêu thụ nông sản hàng hóa. Tuy nhiên, do nhiều nguyên nhân khách quan và chủ quan, chúng ta chưa khai thác hết tiềm năng, lợi thế cho phát triển, vẫn còn rất nhiều những hạn chế, yếu kém, bất cập ở tất cả các khâu trong sản xuất và tiêu thụ nông sản hàng hóa. Trước thềm hội nhập AEC, thị trường nông sản Việt Nam có rất nhiều cơ hội để phát triển, nhưng cũng có không ít thách thức đặt ra. Để tận dụng các cơ hội, vượt qua thách thức để nông sản hàng hóa Việt Nam có thể phát triển và hội nhập, cần thực các giải pháp một cách đồng bộ, kịp thời và hiệu quả; Cần có sự quan tâm của các cấp, các ngành, các tổ chức xã hội - nghề nghiệp, người sản xuất, người tiêu dùng; Cần có sự vào cuộc và hợp tác, liên kết mạnh mẽ của bốn nhà: Nhà nước; Nhà khoa học; Nhà doanh nghiệp và Nhà nông.

\section{TÀI LIỆU THAM KHẢO}

\section{Tiếng Anh}

1. Mely Caballero-Anthony. Paul Teng and Belinda Chng, (2013), NTS Policy Brief, ASEAN Economic Community (AEC) 2015: Opportunities and challenges for food security.(1-5)

\section{Tiếng Việt}

1. Quyết định số 124/2012/QĐ-TTg của Thủ tướng Chính phủ về việc quy hoạch tổng thể phát triển sản xuất ngành nông nghiệp đến năm 2020 và tầm nhìn đến 2030.

2. Bộ Nông nghiệp và Phát triển nông thôn, (2015), Báo cáo kết quả thưc hiện kế hoạch tháng 7/2015 ngành Nông nghiệp và phát triển nông thôn.

3. Trung tâm Thông tin phát triển nông nghiệp nông thôn (2014), Báo cáo thường niên ngành nông nghiệp, Nông nghiệp Việt Nam 2014, triển vọng 2015.

4. Trần Chí Thành (2001), Các chính sách thúc đẩy xuất khẩu nông sản Việt Nam trong thời gian tới, Trường Đại học Kinh tế quốc dân.

5. Nguyễn Thị Tâm ( 2014), Cơ hội và thách thức của Việt Nam khi gia nhập cộng đồng kinh tế ASEAN, Bộ Lao động Thương binh \& Xã hội. 